\title{
Pattern electroretinogram and automated perimetry in patients with glaucoma and ocular hypertension
}

\author{
Christopher Neoh, Stephen B Kaye, Malcolm Brown, Alec M Ansons, Peter Wishart
}

\begin{abstract}
To determine whether the pattern electroretinogram can improve the objectivity of visual field assessment, 39 patients with glaucoma and ocular hypertension were studied. This was to establish whether there is a correlation between the pattern electroretinogram and the global indices (mean deviation and corrected pattern standard deviation) provided by automated perimetry using the Humphrey visual field analyser. A significant correlation was found between the amplitude of the P50+N95 wave of the pattern electroretinogram and the mean deviation and corrected pattern standard deviation components of the visual field. The larger the deviation from normal of these indices, particularly the corrected pattern standard deviation, the smaller the amplitude of the pattern electroretinogram. This correlation between the pattern electroretinogram and visual field indices provides an additional measure of confidence when interpreting equivocal results of automated perimetry.
\end{abstract}

(Brf Ophthalmol 1994; 78: 359-362)

The pattern electroretinogram (PERG) has been shown to be affected in patients with glaucoma and ocular hypertension $(\mathrm{OH}){ }^{1-12}$ Wanger and Persson found a difference in the amplitude of the PERG between the eyes of patients with asymmetric glaucoma, ${ }^{1}$ and there have been several subsequent studies showing a difference in the components of the PERG between glaucomatous, $\mathrm{OH}$, and normal eyes. ${ }^{1-12}$

The diagnosis of glaucoma in a patient who has mildly elevated intraocular pressure (IOP) is dependent upon the detection of glaucomatous optic disc damage and/or typical visual field defects. In those situations where the optic disc appears normal on biomicroscopy, but visual field testing shows an equivocal field defect, it would be helpful to know whether the visual field defect is supported by the PERG. Wanger and Persson were able to show a correlation between the PERG and the Goldmann visual field of eyes of patients with asymmetric glaucoma. ${ }^{1}$ In a later study they were able to correlate computer assisted and high pass resolution perimetry with the amplitude of the PERG. ${ }^{6}$ In contrast, Drance et al were unable to improve their multivariate regression analysis between visual field, colour vision, contrast sensitivity, and disc parameters by including the PERG. ${ }^{7}$ Van der Berg et al were also unable to find changes in the PERG as a function of field. ${ }^{4}$ O'Donaghue et al found, however, that the sensitivity and specificity of their criteria for PERG analysis, compared well with automated perimetry, although data from the latter were not stated. ${ }^{3}$ In order to determine whether a correlation exists between the visual field using automated perimetry (Humphrey visual field analyser, STATPAC 2 analysis) and the PERG, patients with glaucoma and $\mathrm{OH}$ were studied.

It has been suggested that because the PERG is affected in patients with $\mathrm{OH}$, an abnormal PERG is an indicator of retinal damage not apparent on automated perimetry. We were therefore interested to ascertain whether the PERG was predictive of those patients with $\mathrm{OH}$ who subsequently developed glaucoma.

\section{Methods}

Patients from the glaucoma clinic at St Paul's Eye Unit with asymmetrical glaucoma or $\mathrm{OH}$ were entered into the study.

Patients' eyes were classified into two groups, by one of the authors (PKW), namely, those with

(a) established glaucoma - that is, raised IOP above $21 \mathrm{~mm} \mathrm{Hg}$, evidence of glaucomatous damage of the optic disc using stereoscopic slitlamp biomicroscopy, and coexistent visual field defects;

(b) $\mathrm{OH}$ or suspected glaucoma - that is, raised IOP above $21 \mathrm{~mm} \mathrm{Hg}$, normal appearing optic discs, and normal or equivocal visual fields.

A control group of 18 healthy people was also recruited from hospital staff for PERG analysis.

\section{EXCLUSION CRITERIA}

Patients were excluded if the visual acuity at recording of the PERG was less than $6 / 12$ or if other non-glaucomatous eye disease was present.

The PERG was recorded from both eyes of each patient on entry into the study, and the visual field recorded within 2 months.

\section{VISUAL FIELD ANALYSIS}

The Humphrey visual field analyser ${ }^{13-15}$ was used to record the visual field. Only those patients who had visual field analysis using either the $24-2$ or 24-1 threshold test (STATPAC 2) ${ }^{13}$ were included in the correlation analysis with the PERG. The corrected pattern standard deviation (CPSD) and overall mean deviation (MD) were the indices recorded for correlation analysis with PERG. Visual fields were not used for analysis if fixation losses, false positive or false negative errors exceeded $30 \%$, or if there was recognisable artefact.

\section{PERG}

This was recorded using a gold foil electrode over the junction of the mid and lateral third of the 
Figure 1 The PERG. The amplitude of the $P 50+N 95$ wave is measured from the peak of the wave occurring at approximately $50 \mathrm{~ms}$ to the trough of the wave occurring at approximately $95 \mathrm{~ms}$ as shown; $(A)$ normal fellow eye, $(B)$ ocular hypertensive eye.

B
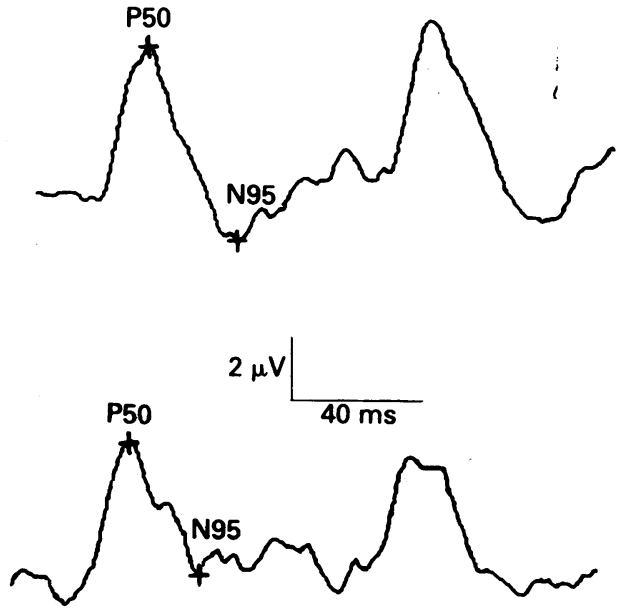

lower lid. ${ }^{16}$ The reference electrode was placed on the ipsilateral temple. A television screen subtending an angle of $28^{\circ} \times 21.5^{\circ}$ at the eye at a distance of $0.5 \mathrm{~m}$ was used to provide a pattern reversal stimulus. The checks subtended an angle of $0.89^{\circ}(0.56 \mathrm{cpd})$ at $97.8 \%$ contrast $\left(\mathrm{L}_{\min }=2 \cdot 1 \mathrm{~cd} / \mathrm{m}^{2}, \mathrm{~L}_{\max }=187 \cdot 1 \mathrm{~cd} / \mathrm{m}^{2}\right)$. There were 7.9 reversals per second $(4 \mathrm{~Hz}), 200$ sweeps were averaged per response, and two recordings averaged. A time base of $200 \mathrm{~ms}$ was used so as to record two consecutive PERGs. A Nicolet compact four electrodiagnostic system was used to record the PERG. The amplitude of the $\mathrm{P} 50+\mathrm{N} 95$ wave was measured from the peak of the wave occurring at $50 \mathrm{~ms}$ to the trough of the wave occurring at $95 \mathrm{~ms}^{2}$ (see Fig 1). In order to measure the P50 and N95 components of this wave, a baseline was drawn parallel to a line connecting the peaks of two successive P50 waves. The amplitude of the P50 was then measured from this line to the peak of the wave at $50 \mathrm{~ms}$ and the N95 amplitude from this line to the trough of the wave occurring at $95 \mathrm{~ms}$. Because of the inherent difficulty in locating the baseline, all statistical analysis was on the $\mathrm{P} 50+\mathrm{N} 95$ wave amplitude, which was more reliably determined. All measurements were recorded for later analysis. The PERG results for patients' right and left eyes were analysed separately.

CORRELATION ANALYSIS

One eye of each patient was used for regression

Table 1 Number of patients with glaucoma and ocular hypertension

\begin{tabular}{lcc}
\hline & Glaucoma & $\begin{array}{l}\text { Ocular } \\
\text { hypertension }\end{array}$ \\
\hline Both eyes & 4 & 8 \\
One eye & 24 & 26 \\
\hline
\end{tabular}

Table 2 Average PERG and visual field indices of right eyes (SD)

\begin{tabular}{lllccc}
\hline & $P 50 \mu V$ & $N 95 \mu V$ & $P 50+N 95 \mu V$ & $M D$ & $C P S D$ \\
\hline Glaucoma & 2.75 & 0.69 & 3.44 & -5.91 & 6.92 \\
Ocular hypertension & 3.55 & 1.31 & $(1.51)$ & $(3.81)$ & $(3.60)$ \\
Control & 5.32 & 2.16 & $(1.90$ & -2.07 & 2.99 \\
& & & 7.48 & $(2.31)$ & $(2.20)$ \\
& & & & \\
\hline
\end{tabular}

$\mathrm{MD}=$ mean deviation $; \mathrm{CPSD}=$ corrected pattern standard deviation . analysis. This was then repeated using the fellow eye. A correlation analysis was performed using all the CPSD and MD values of eyes that had had either a $24-1$ or 24-2 threshold test. This was then repeated using only those eyes that had MD and CPSD values that were significant at the $5 \%$ level.

FOLLOW UP

All patients were followed up for at least 2 years to determine clinical outcome. Where three or more consecutive visual fields using the 24-2 threshold test were available, a box plot analysis (STATPAC 2) of the MD was determined.

\section{STATISTICAL ANALYSIS}

Non-paired Student's $t$ test was used for comparison of group means and linear least squares regression analysis for CPSD, MD, and PERG correlation.

\section{Results}

Thirty nine patients were recruited into the study. Four eyes were excluded because of other ocular disease. There were 34 patients (42 eyes) with $\mathrm{OH}$ or suspected glaucoma and 28 patients (32 eyes) with glaucoma (Table 1). The mean intraocular pressures at presentation of those patients with $\mathrm{OH}$ and glaucoma were $25.7 \mathrm{~mm}$ $\mathrm{Hg}$ (range $23-30 \mathrm{~mm} \mathrm{Hg}$ ) and $27.17 \mathrm{~mm} \mathrm{Hg}$ (range $23-32 \mathrm{~mm} \mathrm{Hg}$ ) respectively. The average age (and range) of the patients in the $\mathrm{OH}$, glaucoma, and control groups whose right eyes were used for analysis was $67 \cdot 4$ years (51-81), $62 \cdot 4$ years (42-76), and $40 \cdot 6$ years $(20-63)$ respectively.

\section{TREATMENT AT TIME OF RECORDING}

At the time of recording the PERG and the visual field, eight of 74 eyes were not on treatment, 11 were on both pilocarpine and timolol (five right and six left), four eyes had had trabeculectomies, and the remaining 51 eyes were on topical $B$ blockers (47 on timolol).

VISUAL FIELD ANALYSIS

Thirty one out of 39 patients (60 eyes) had 24-1 or 24-2 threshold tests. Eight patients did not have 24-1 or 24-2 threshold tests at the time of recording the PERG and were therefore not used for correlation analysis with the PERG. Six of these eight patients had Armaly screening tests on the Humphrey visual field analyser at the time of the PERG. The other two patients had nonautomated perimetry (Henson CFS2000 and Friedman Mk 2). Results show a significant difference in both the MD and the CPSD between patients with $\mathrm{OH}$ and those with glaucoma ( $p=0.001$ and $p=0.0001$ respectively).

PERG

There were 70 eyes with reliable PERGs. Two eyes were excluded because of substantial artefact. 
There was a significant difference between the average $\mathrm{P} 50+\mathrm{N} 95$ for the glaucoma and $\mathrm{OH}$ groups. For right eyes, the average $\mathrm{P} 50+\mathrm{N} 95$ was $3.44 \mu \mathrm{V}$ (SD 1.51) and $4.86 \mu \mathrm{V}(1.90)$, $\mathrm{p}=0.024$ respectively, and for left eyes, $3.47 \mu \mathrm{V}$ $(1.52)$ and $4.96 \mu \mathrm{V}(1.81), p=0.0 .16$ respectively (Table 2).

This analysis was repeated after excluding the eyes of those patients receiving pilocarpine (five right and six left). There was still a significant difference between the glaucoma and $\mathrm{OH}$ groups - that is, $3.53 \mu \mathrm{V} v 4.99 \mu \mathrm{V}(\mathrm{p}=0.028)$ and 3.26 $\mu \mathrm{V} v 5.2 \mu \mathrm{V}(\mathrm{p}=0.005)$, right and left eyes respectively.

There was also a significant difference between the mean P50+N95 of the control group (7.48 $\mu \mathrm{V}(2.02)$ and $7.73 \mu \mathrm{V}(1.93)$ right and left eyes respectively) and the $\mathrm{OH}$ group ( $t$ test $\mathrm{p}=0.0002, \mathrm{p}=0.0001$, respectively).

\section{CORRELATION ANALYSIS}

There were 60 eyes with either 24-1 or 24-2 visual field threshold tests, 58 of which had reliable visual fields.

There were 56 eyes with reliable threshold tests and PERGs. There was a significant correlation between both the CPSD and MD and the amplitude of the P50+N95 wave of the PERG (best fit linear least squares regression line):
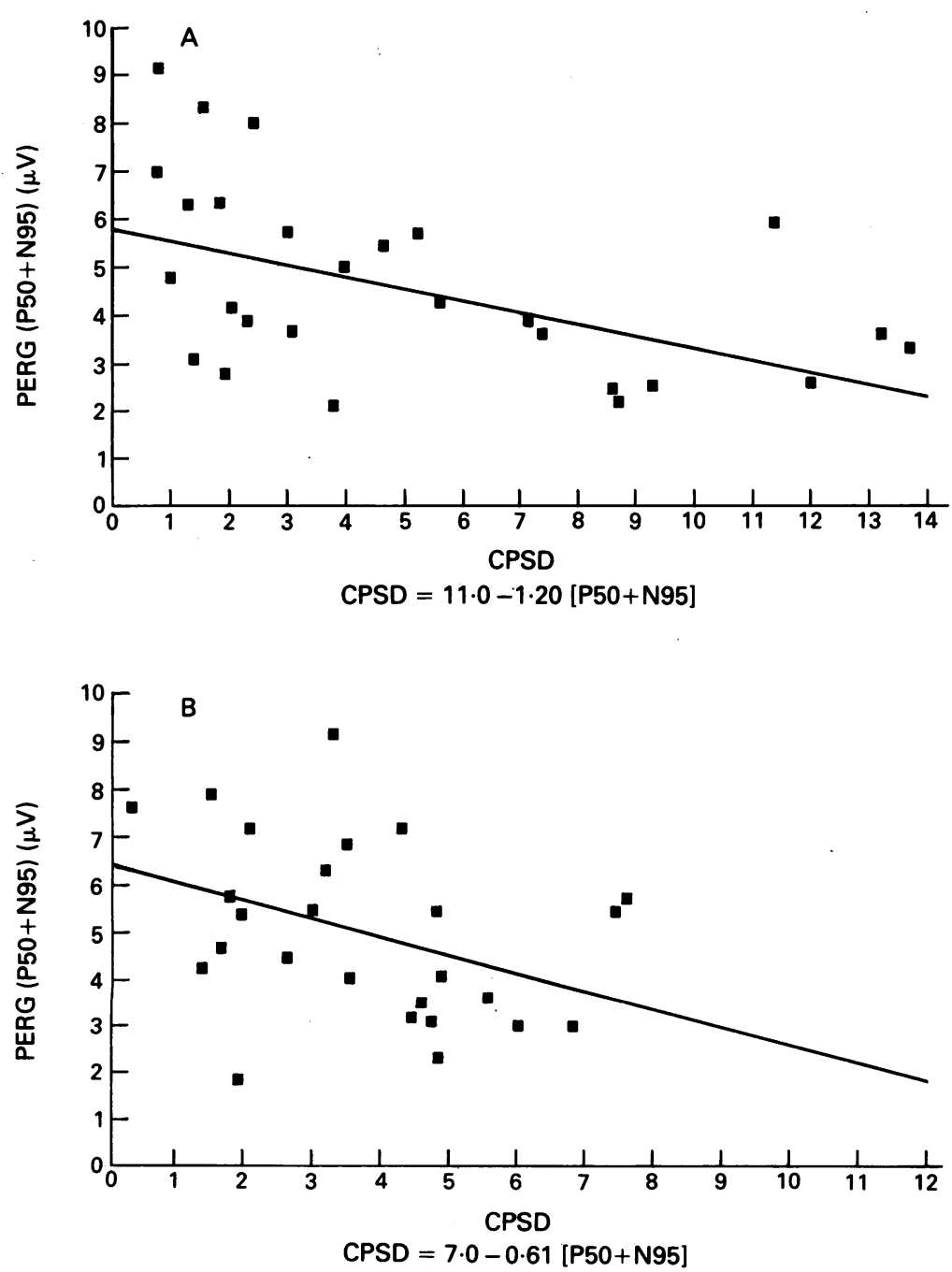

Figure 2 The amplitude of the P50+N95 wave of the PERG in $\mu V$ is plotted as a function of the corrected pattern standard deviation $(C P S D) ;(A)$ right eyes, $(B)$ left eyes.
$\mathrm{CPSD}_{\text {right }}=11 \cdot 0-1 \cdot 20[\mathrm{P} 50+\mathrm{N} 95]\left(r^{2}=0 \cdot 30, \mathrm{p}=0 \cdot 001\right)$ $\mathrm{CPSD}_{\text {reft }}=7 \cdot 0-0.61[\mathrm{P} 50+\mathrm{N} 95]\left(r^{2}=0.22, \mathrm{p}=0.01\right)$

(Fig $2 \mathrm{~A}$ and $\mathrm{B}$ )

$\mathrm{MD}_{\text {riqh }}=-9 \cdot 6+1 \cdot 18[\mathrm{P} 50+\mathrm{N} 95] \quad\left(r^{2}=0 \cdot 29, \mathrm{p}=0.002\right)$

$M_{\text {kft }}=-8 \cdot 7+1 \cdot 14[\mathrm{P} 50+\mathrm{N} 95] \quad\left(r^{2}=0 \cdot 36, \quad \mathrm{p}=0.001\right)$

This correlation between the CPSD, MD, and PERG remained after excluding the eyes of those patients on pilocarpine - that is, CPSD and PERG $\left(r^{2}=0.35, p=0.002\right.$ and $r^{2}=0.21$, $\mathrm{p}=0.03$, right and left eyes), and between MD and PERG $\left(r^{2}=00.39, \mathrm{p}=0.001\right.$ and $r^{2}=0.34$, $p=0.003$, right and left eyes respectively).

\section{CORRELATION WITH SIGNIFICANT VISUAL FIELD}

INDICES

This correlation was further analysed by only including those eyes which had significant CPSDs and MDs as follows.

There were 39 eyes with significant field loss shown by either CPSD, MD, or both at the $5 \%$ level. The 34 eyes with significant MDs and the 39 eyes with significant CPSDs were then correlated with the corresponding $\mathrm{P} 50+\mathrm{N} 95$ wave of the PERG.

There was no correlation between significant MD and the P50+N95. There was, however, a significant correlation between the CPSD of the visual field and the amplitude of the P50+N95 wave of the PERG for both left and right eyes $(\mathrm{p}<0.05)$ :

$\mathrm{CPSD}_{\text {right }}=12 \cdot 8-1 \cdot 24[\mathrm{P} 50+\mathrm{N} 95] \quad\left(r^{2}=0.30, \mathrm{p}=0.012\right)$ $\mathrm{CPSD}_{\text {kfft }}=7.66-0.589[\mathrm{P} 50+\mathrm{N} 95]\left(r^{2}=0.22, \mathrm{p}=0.034\right)$

CLINICAL OUTCOME

Two eyes initially classed as $\mathrm{OH}$ developed glaucomatous visual field damage by the 2 year follow up. Because of this small sample size, follow up correlation analysis between the PERG and the visual field at this time was not possible.

\section{Discussion}

The amplitude of the PERG has been shown to be differentially affected in glaucoma and $\mathrm{OH} .^{1-12}$ Several studies have found the P50 and N95 components of the PERG to be separately affected in such patients, although there have been conflicting results. ${ }^{417}$ The results of this study suggest that the $\mathrm{P} 50+\mathrm{N} 95$ component of the PERG allows separation of patients with glaucoma, $\mathrm{OH}$, and no disease as individual groups consistent with previous studies. ${ }^{1-36-12}$ The usefulness of the PERG in glaucoma suspects, however, may be dependent on the spatial frequency and mean luminance used. ${ }^{38111218-20}$ The PERG is also dependent on contrast, temporal frequency, and size of the field, ${ }^{810^{17-19}}$ which may to a certain extent account for some of the differences observed in the previous studies. ${ }^{1-8}$

The results of Hess and Baker, ${ }^{18}{ }^{19}$ Maffei and Fiorentini, ${ }^{20}$ Fiorentini et al ${ }^{21}$ and Dawson et al ${ }^{22}$ indicate that the PERG response originates postreceptorally, probably reflecting ganglion cell activity. ${ }^{23}$ The PERG may therefore be a useful objective way of complementing the visual field in the assessment of the glaucoma suspect.

Wanger and Persson recorded visual fields 
using a Goldmann perimeter (Haag-Streit, type 940) using a static suprathreshold technique. ${ }^{1} \mathrm{~A}$ score of 0 was recorded if III: 1 was seen, -1 if III: 3 was perceived, and -2 if no stimulus was seen. They used 52 locations - that is, a score of 0 to -104 . A clear relation was found between the visual field defect and the PERG with a correlation coefficient of -0.69 , whether from the central $10^{\circ}$ or from $30^{\circ}$ fields. Watanabe et al, however, found that the ratio of the central to paracentral PERG to be a more useful indicator of glaucomatous damage. ${ }^{10}$

In a subsequent study, Wanger and Persson compared the PERG with computer assisted perimetry and high pass resolution perimetry. ${ }^{6}$ They matched eyes with abnormal PERGs and abnormal high pass resolution perimetry and computer assisted perimetry. A concordance was found between the PERG and high pass resolution perimetry of $71 \%$ and between the PERG and computer assisted perimetry of $33 \%$. Drance et al used multivariate analysis to assess the correlation between neuroretinal rim, cup/disc ratio, visual fields (Jo program of the Octopus 201 perimeter), colour vision, contrast sensitivity, visual evoked potentials, and the PERG (using a mean luminance of $29 \mathrm{~cd} / \mathrm{m}^{2}$ ). ${ }^{7}$ In contrast to Wanger and Persson ${ }^{6}$ they found that inclusion of the PERG in the analysis did not alter (improve) the regression analysis, although the number of eyes with completed PERG recordings is not stated. ${ }^{7}$

The MD of the visual field is a variance weighted average difference of observed threshold sensitivity from the age-specific normal sensitivity. ${ }^{1322}$ A large negative $M D$ indicates an overall abnormality of the visual field. The CPSD estimates the extent of localised visual field defects, adjusted to reflect only irregularities in the field that are greater than those generated by measurement error alone (large CPSD suggests localised defects). ${ }^{24} \mathrm{Katz}$ et al, when comparing global indices, found that if the PSD or CPSD was more extreme than that found in $5 \%$ of the normal population, a sensitivity of $91 \%$ and specificity of $84 \%$ was achieved, thus aiding in the detection of glaucomatous field defects. ${ }^{24}$ Global indices of the visual field, however, such as the CPSD and MD can be difficult to interpret. A large depression at one or two points in the field whether due to artefact or not, may significantly affect the overall MD or CPSD. The results of this study suggest that the $\mathrm{P} 50+\mathrm{N} 95$ component of the PERG can be correlated with the overall MD and CPSD of the automated visual field. The lack of significance between significant $M D$ and PERG values may reflect a loss of specificity of the MD for glaucomatous defects compared with the CPSD. This is, in part, supported by the fact that significance was reached when all eyes with an MD were included in analysis thereby increasing the sample size. The correlation between the PERG and signifi- cant CPSD but not $M D$ values ( $5 \%$ level) reflects the usefulness of the relation between the PERG and the CPSD in interpreting the visual field. The concordance between the PERG and visual field as previously suggested ${ }^{136}$ thus allows an additional objective measure of confidence when interpreting the visual field, particularly in those situations when the field is equivocal or the patient unreliable.

1 Wagner $P$, Persson HE. Pattern-reversal electroretinograms in unilateral glaucoma. Invest Ophthalmol Vis Sci 1983; 24: 749-53.

2 Weinstein GW, Arden GB, Hitchings RA, Ryan S, Calthorpe CM, Odom JV. The pattern electroretinogram (PERG) in ocular hypertension and glaucoma. Arch Ophthalmol 1988; 106: 923-8.

3 O'Donoghue E, Arden GB, O'Sullivan F, Falcao-Reis F Moriarty B, Hitchings RA, et al. The pattern electroretinogram in glaucoma and ocular hypertension. Br $\mathcal{f} O$ phthalmol 1992; 76: 387-94.

4 Van den Berg TJTP, Riemslag FCC, de Vos GWGA. Pattern ERG and glaucomatous visual field defects. Doc Ophthalmol 1986; 61: 335-41.

5 Ohta $\mathrm{H}$, Tamura $\mathrm{T}$, Kawasaki $\mathrm{K}$. Negative wave in human pattern ERG and its suppression in glaucoma. Acta Soc Ophthalmol fpn 1986; 90: 882-6.

6 Wanger P, Persson HE. Pattern-reversal electroretinograms from normotensive, hypertensive and glaucomatous eyes. Ophthalmologica 1987; 195: 205-8.

7 Drance SM, Airaksinen PJ, Price M, Schlzer M, Douglas GR Tansley BW. The correlation of functional and structural Tansley BW. The correlation of functional and structural measurements in glaucoma patients

8 Pffeifer N, Birkner-Binder D, Bach M. Das Muster-ERG bei okularer Hypertension und Glaukom. Einfluss von Karogrosse, Kontrast und retinaler Exzentrizitat. FortschrOphthalmol 1991; 88: 815-8.

9 Holder GE. Significance of abnormal pattern electroretinography in anterior visual pathway dysfunction. Brf Ophthalmol 1987; 71: 166-71.

10 Watanabe I, Ijjima $\mathrm{H}$, Tsukahara S. The pattern electroretinogram in glaucoma: an evaluation by relative amplitude from the Bjerrum area. Br f Ophthalmol 1989; 73: 131-5.

11 Bach $M$, Hiss P, Rover J. Check-size specific changes of pattern electroretinogram in patients with early open angle pattern electroretinogram in patients with ea
glaucoma. Doc Ophthalmol 1988; 69: 315-22.

12 Portiatti V, Falsini B, Brunori S, Colotto A, Moretti G. Pattern electroretinogram as a function of spatial frequency in ocular hypertension and early glaucoma. Doc Ophthalmol 1987; 65: 349-55.

13 Heijl A, Lindgren G, Lindgren A, Asman P, Olsson J, Myers $S$. Extended empirical statistical package for evaluation of single and multiple fields in glaucoma: Statpac 2. In: Mills RP, Heijl A, eds. Perimetry update 1990/91 (Proceedings of the IX International Perimetric Society, 12 June 1990). New York: Kugler Publications, 1991: 303-15.

14 Heijl A, Lindgren A, Lindgren G. Test-retest variability in glaucomatous visual fields. Am $\mathcal{F}$ Ophthalmol 1990; 109 : 110.

15 Heijl A, Lindgren A, Lindgren G. Test-retest variability in glaucomatous visual fields. Am $\mathcal{F}$ Ophthalmol 1989; 108: glaucor

16 Arden GB, Carter RM, Hogg C, Siegel IM, Margolis S. A gold oil electrode: extending the horizons for clinical electroretinography. Invest Ophthalmol Vis Sci 1979; 18: 421.

17 May JG, Ralston JV, Reed JL. Loss in pattern-elicited electroretinograms in optic nerve dysfunction. Am $\mathcal{F} O p h$ thalmol 1982; 93: 418-22.

18 Hess RF, Baker CL. Human pattern-evoked electroretinogram. f Neurophysiol 1984; 51: 939-51.

19 Baker CL, Hess RF. Linear and nonlinear components of human electroretinogram. F Neurophysiol 1984; 51: 953-67.

$20 \mathrm{Maffei} \mathrm{L}$, Fiorentini A. Electroretinographic responses to alternating gratings before and after section of the optic nerve. Science 1981; 211: 953-4.

21 Fiorentini A, Maffei L, Pirchio M, Spinelli D, Porciatti V. The ERG in response to alternating gratings in patients with ERG in response to alternating gratings in patients with
diseases of the peripheral visual pathway. Invest Ophthalmol diseases of the peripheral
$V$ is $S c i$ 1981; $21: 490-3$.

22 Dawson WW, Maida TM, Rubin ML. Human pattern-evoked retinal responses are altered by optic atrophy. Invest Ophthalmol Vis Sci 1982; 72: 796-803.

23 Berninger TA, Arden GB, Hogg CR, Frumkes TE. Separable evoked retinal and cortical potentials for each major visual pathway: preliminary results. $\mathrm{Br} \mathcal{F}$ Ophthalmol 1989; 73: 502-12.

24 Katz J, Sommer A, Gaasterland DE, Anderson DR. Comparifield loss. Arch Ophthalmol 1991; 109: 1684-89. 